\title{
TUTUPAN LAHAN GAMBUT MEMPENGARUHI KONDISI IKLIM MIKRO DI SEKITAR KAMPUS UNIVERSITAS PALANGKA RAYA (Preliminary Data Integrasi Wireless Sensor Network) The Peatland Cover Impact Micro Climate Conditions Near Campus of the University of Palangka Raya (Preliminary Integration Data of Wireless Sensor Network)
}

\author{
Adji, F.A., ${ }^{1 *)}$ dan Teguh, R., ${ }^{2)}$ \\ ${ }^{1)}$ Prodi Agroteknologi Jurusan Budidaya Pertanian Fakultas Pertanian Universitas Palangka Raya \\ ${ }^{2)}$ Staf Pengajar JurusanTeknik Informatika, Fakultas Teknik, Universitas Palangka Raya \\ Telp. $085750133829 *$ *orresponding author : fengky@agr.upr.ac.id
}

Disetujui :15/08/2018_ Disetujui : 09/09/2018

\begin{abstract}
The lack of field measurements, which collected in long period and significantly spatial effect on the environments can obstruct scientific understanding the effect of environmental condition on the ecosystems. Application wireless sensor network (WSN) is useful to address the situation through low cost wireless measurement sensors and minimize disruption to the location/conditions to be monitored. The comprehension of composition transformation, structure, the environment ecosystems dynamic, and how is the transformation of all can be affecting the human life, indeed this challenge are need detail analysis of all environment ecosystem elements. This study also review the uses of smart devices wireless sensor networks (WSN), and observe the underlying technology in hopes could be giving solve or determine the condition of environment and ecosystems affected by human activity. The results of this study showed that the land use cover is influence on the environment conditions.
\end{abstract}

Keywords: Wireless sensor networks (WSN), ecosystems, and environment

\begin{abstract}
ABSTRAK
Kekurangan pengukuran lapangan (lack of field measurements), yang dikumpulkan dalam jangka waktu lama dan efek spasial yang sangat nyata pada lingkungan, menghalangi pemahaman ilmiah tentang pengaruh kondisi lingkungan terhadap suatu ekosistem. Aplikasi wireless sensor networks(WSN) sangat menjanjikan untuk mengatasi keadaan tersebut melalui sensor pengukuran nirkabel yang berbiaya murah dan meminimalkan gangguan terhadap lokasi/kondisi yang akan dimonitor/dipantau. Pemahaman perubahan komposisi, struktur, dan dinamika suatu ekosistem dan lingkungan, serta bagaimana perubahan tersebut mempengaruhi kehidupan manusia, tentu saja tantangan ini membutuhkan analisis yang detail dari berbagai elemen fisik dan biotik suatu lingkungan dan ekosistem di dalamnya. Penelitian ini mengulas kegunaan lain dari wireless sensor networks (WSN), dan meninjau teknologi yang mendasarinya dengan harapan akan merangsang penggunaan teknologi untuk mengatasi atau mengetahui kondisi lingkungan dan ekosistem yang terkena dampak oleh kegiatan yang dilakukan oleh aktivitas manusia. Hasil penelitian menunjukkan bahwa tutupan lahan akan mempengaruhi fluktuasi/perubahan kondisi lingkungan sekitar

Kata kunci : Wireless sensor networks (WSN), ekosistem, dan lingkungan
\end{abstract}




\section{PENDAHULUAN}

Pemahaman perubahan komposisi, struktur, dan dinamika suatu ekosistem dan lingkungan, serta bagaimana perubahan tersebut mempengaruhi kehidupan manusia, tentu saja tantangan ini membutuhkan analisis yang detail dari berbagai elemen fisik dan biotik suatu lingkungan dan ekosistem di dalamnya (Hamilton, 2004; Porter et al., 2005).

Ahli biologi dan ekologi mulai membuka jalan baru penyelidikan yang lebih besar skala spasial dan temporalnya.Jaringan sensor memfasilitasi koleksi beragam jenis data (suhu, pencitraan, dan suara) pada setiap interval, ataupun dengan jeda waktu pada skala yang luas, memungkinkan ahli biologi dan ekologi untuk terlibat dalam pengambilan data yang lebih intensif dalam skala luas.

Saat ini teknologi wireless sensor networks (WSN) merupakan teknologi yang dapat digunakan untuk memantau dan mengontrol fenomena perilaku lingkungan, dimana setiap perangkat node sensor terdiri atas: perangkat komputasi dan perangkat komunikasi tanpa kabel yang diletakan pada lingkungan yang akandipantau secara terusmenerus. Perangkat WSN dapat mengumpulkan dan mendistribuskan informasi lingkungan tersebut melalui radio yang terpasang pada sensor node (Akyildiz et al., 2002). Teknologi ini adalah satu teknologi multiguna yang dapat diaplikasi baik pada industri, logistik, konstruksi, transportasi, kesehatan serta lingkungan hidup (Abd ElKader and Mohammad El-Basioni, 2013; Teguh et al., 2012; Zhou et al., 2007).

Selain itu, data langsung (realtime) memungkinkan peneliti untuk bereaksi dengan cepat terhadap suatu peristiwa selama kegiatan penelitian berlangsung. Penelitian ini juga mengulas kegunaan lain dari wireless sensor networks (WSN), dan meninjau teknologi yang mendasarinya dengan harapan akan merangsang penggunaan teknologi untuk mengatasi atau mengetahui kondisi lingkungan dan ekosistem yang terkena dampak oleh kegiatan yang dilakukan oleh aktivitas manusia.

Hutan rawa gambut merupakan sumber kehidupan bagi semua makhluk hidup, terkhusus ekosistem gambut.Dengan adanya hutan, simbiosis dan rantai kehidupan makhluk hidup dapat berjalan.Alih fungsi lahan gambut dan kerusakan hutan gambut menjadi masalah serius yang dihadapi dewasa ini.Jika ditinjau dari segi perkembangan teknologi saat ini, program kelestarian ekosistem hutan rawa gambut cenderung memerlukan suatu sistem yang mampu menganalisa dan memonitoring adanya indikasi perubahan lingkungan ekosistem dan alih fungsi hutan rawa gambut.Teknologi nirkabel (wireless) yang mampu mengirimkan data tanpa perlu menggunakan kabel diharapkan mampu menjadi salah satu perkembangan teknologi aplikatif yang dapat mendukung program kelestarian hutan rawa gambut.Sistem monitoring ini diharapkan mampu menyajikan suatu data berupa indikasi perubahan lingkungan atau potensi kebakaran untuk lahan yang luas sekalipun.

Wireless sensor network (WSN) merupakan suatu kesatuan dari proses pengukuran, komputasi, dan komunikasi yang memberikan kemampuan administratif kepada sebuah perangkat, observasi, dan melakukan penanganan terhadap setiap kejadian dan fenomena yang terjadi di lingkungan yang mengunakan teknologi nirkabel (wireless). Sistem ini jauh lebih efisien dibandingkan dengan penggunaan kabel.Sistem ini memiliki fungsi untuk berbagai jenis aplikasi, dalam arti lain, WSN menyediakan pondasi teknologi untuk melakukan eksperimen pada lingkungan..

\section{BAHAN DAN METODE}

Komponen WSN meliputi: sensor, modul wireless, dan Personal Computer (desktop/laptop). Seluruh komponen akan membentuk suatu sistem monitoring yang mampu menampilkan data berupa hasil pengukuran beberapa sensor karakteristik lingkungan sekitar yang digunakan dengan memanfaatkan media wireless. Karena dapat digunakan untuk berbagi aplikasi, penggunaan jenis sensor dipilih berdasarkan aplikasinya (sensor untuk temperatur udara, kelembaban udara, dan intensitas cahaya). Penelitian ini dilaksanakan pada hari Rabu, tanggal 10 
Desember 2014, mulai pukul 09.00 - 12.00 WIB, bertempat di sekitar gedung Laboratorium Dasar dan Analitik, Universitas Palangka Raya (UPR), dengan koordinat $2^{\circ} 12^{\prime} 55.77 " \mathrm{~S}$ dan $113^{\circ} 53^{\prime} 58.91^{\prime \prime} \mathrm{E}$, pada 5 (lima) lokasi penelitian, yaitu : lokasi open area, homogen forest/big diameter, homogen forest/small diameter, big tree, dan small tree.

Sedangkan untuk mengetahui persentase cahaya yang masuk dan persentase kanopi (canopy) pohon/tanaman diolah dengan menggunakan metode pengolahan citra (image processing), yang mana photo kanopi (canopy) pohon/tanaman diambil dari bagian bawah pohon/tanaman menggunakan kamera digital (5 mega pixel) Ipod Touch ${ }^{\circledR}$ Apple $32 \mathrm{~Gb}$, selanjutnya dianalisis dengan algoritma canopy binary menggunakan software Matlab $\odot$ 1994-2015.The MathWorks, Inc. Dimana algoritma menghitung jumlah warna hitam diidentifikasikan dengan angka 1 (tutupan) dan warna putih diidentifikasikan dengan angka 0 (cahaya/sinar).Untuk saat ini photo kanopi pohon/tanaman hanya diambil pada lokasi homogen forest/small diameter dan homogen forest/big diameter..

\section{HASIL DAN PEMBAHASAN}

Berdasarkan Gambar 1 di atas terlihat bahwa terjadi peningkatan temperatur udara dan penurunan kelembaban udara selama kurun waktu pengukuran (09.29 11.55 WIB) dengan menggunakan metode wireless sensor network (WSN), yang ditunjukkan dengan data langsung (realtime).

Tutupan lahan yang membentuk kanopi (canopy) pada permukaan lahan akan turut mempengaruhi perubahan/fluktuasi parameter lingkungan, salah satunya adalah cahaya/sinar matahari yang sampai ke permukaan tanah (Gambar 2 dan 3). Dari hasil perhitungan dengan menggunakan software Matlab $\odot 1994$ - 2015. The MathWorks, Inc menunjukkan bahwa pada lokasi homogen forest/small diameter, luas permukaan tanah yang tertutup kanopi pohon/tanaman adalah $66.5 \%$ yang menyebabkan cahaya/sinar matahari yang sampai di bawahnya adalah $33.5 \%$ (dengan intensitas cahaya hasil dari evaluasi menggunakan sensor intensitas cahaya pada WSN, yaitu 81.25 lux). Sedangkan pada lokasi homogen forest/big diameter, luas permukaan tanah yang tertutupi kanopi pohon/tanaman adalah $70.2 \%$ yang menyebabkan cahaya/sinar matahari yang sampai ke permukaan tanah adalah $29.8 \%$ (dengan intensitas cahaya hasil dari evaluasi menggunakan sensor intensitas cahaya pada WSN, yaitu 31.97\%). Dari hasil intepretasi menggunakan algoritma canopy binary ini terlihat bahwa tutupan lahan akan mempengaruhi kondisi lingkungan sekitarnya.

Proses fotosintesis yang terdapat pada tumbuhan hijau yang bersifat autotrof diartikan mempunyai kemampuan menyusun makanannya sendiri. Melalui daun, tumbuhan menyerap molekul karbondioksida $\left(\mathrm{CO}_{2}\right)$ juga air dalam rangka menghasilkan gula dan juga oksigen $\left(\mathrm{O}_{2}\right)$.Tumbuhan yang melakukan proses fotosintesis memerlukan bantuan cahaya matahari. Kemampuan menyerap cahaya tersebut disebabkandaun memiliki zat hijau daun atau klorofil.Klorofil ini sendiri ada di dalam bagian organel bernama kloroplast.Pada bagian daun tumbuhan, terdapat 2 (dua) lapisan sel yang dinamai dengan mesofil.pada bagian ini terdapat kurang lebih setengah juta kloroplast yang tersebar disetiap millimeter persegi. Cahaya matahari selanjutnya akan melewati lapisan epidermis yang tanpa warna kemudian melaju menuju mesofil. Pada bagian inilah sebagian besar kegiatan fotosintesis berlangsung.

Penelitian tentang perilaku fotosistesis pada tanaman terhadap variasi suhu memiliki hubungan erat dengan tekanan atmosfer $\mathrm{CO}_{2}$ dan suhu.Pada umumnya tumbuhan daerah tropis tidak mampu melakukan fotosintesis pada suhu $5^{\circ} \mathrm{C}$, maka meskipun sinar ada, $\mathrm{CO}_{2}$ terpenuhi kegiatan fotosintesis akan terhambat dalam hal ini dapat dikatakan bahwa temperatur merupakan faktor penghambat (limiting factor). Demikian pula $\mathrm{CO}_{2}$ terpenuhi, suhu optimum (antara 10$35^{\circ} \mathrm{C}$ ), tetapi sinar kurang banyak maka fotosintesis juga akan menjadi terhambat, hal ini dikatakan bahwa sinar juga menjadi faktor penghambat proses fotosintesis (Dwijoseputro, 1990). Faktor cahaya, suhu, $\mathrm{CO}_{2}$,air dan zat hara mempengaruhi laju fotosintesis tanaman (Treshow, 1970) dan 
berpengaruh pada kepadatan kanopi ,ukuran dan bentuk daun serta sudut letak daun (Hughes, 1965).

Proses fotosistensi merupakan proses reaksi biokimia pada organisme hidup (tumbuhan), dimana cahaya matahari digunakan oleh organisme hidup untuk mengubah karbohidrat menjadi energi kimia. Pada fase ini sejumlah $\mathrm{CO}_{2}$ akan diserap dan digunakan oleh tumbuhan dan sejumlah $\mathrm{O}_{2}$ akan dilepaskan..

\section{KESIMPULAN}

Dari hasil penelitian dapat disimpulkan bahwa

1. Temperatur udara pada lokasi open area lebih tinggi dibandingkan dengan lokasi lainnya, dimana temperatur udara terendah terdapat pada lokasi homogen forest/big diameter.

2. Kelembaban udara terendah terdapat pada lokasi open area, dan yang tertinggi terdapat pada lokasi homogen forest/big diameter.

3. Terdapat hubungan antara perubahan temperatur udara dan kelembaban udara per satuan waktu pada berbagai lokasi penelitian.

4. Hasil perhitungan algoritma canopy binary menunjukkan kanopi (canopy) pohon/tanaman berperan dalam menghalangi cahaya/sinar matahari yang sampai ke permukaan tanah.

5. Perubahan kondisi lingkungan yang dulunya terkendala berbagai hal, baik spasial maupun temporal dapat diminimalisir dan diamati secara langsung (realtime) dengan menggunakan wireless sensor networks (WSN).

\section{DAFTAR PUSTAKA}

Abd El-Kader, S.M., Mohammad El-Basioni, B.M., 2013. Precision farming solution in Egypt using the wireless sensor network technology. Egypt. Informatics J. 14, 221-233. doi:10.1016/j.eij.2013.06.004.
Akyildiz, I.F., Su, W., Sankarasubramaniam, Y., Cayirci, E., 2002. Wireless sensor networks: a survey. Comput. Networks 38, 393-422. doi:10.1016/S1389-1286(01)00302-4.

Dwijoseputro. 1990. Pengantar Fisiologi Tumbuhan. Penerbit Gramedia. Jakarta.

Hamilton, M. 2004. CENS: New directions in wireless embedded networked sensing of natural and agricultural ecosystems. Converging technologies for agriculture and environment. Sir Mark Oliphant Conference, Melbourne, Australia, Aug $9-12$, 2004.

http://www.jamesreserve.edu/staff/Oli phant_Report.pdf.

Hughes .R. 1965. Climatic factors in relation to growth and survival of pasture plants. J. British Grassland. Soc. 20:263-272.

Porter, J., Berger, A. R., P., Braun, H., Bryant, P., Gage, S., Hansen, T., Hanson, P., Lin, C., Lin, F., Kratz, T., Michener, W., Shapiro S., and Williams, T. 2005. Wireless sensor networks for ecology. BioScience, 55, 561.

Teguh, R., Honma, T., Usop, A., Shin, H., Igarashi, H., 2012. Detection and verification of potential peat fire using wireless sensor network and UAV. Proceeding Int. Conf. Inf. Technol. Electr. Eng. 6-10.

Treshow. K.M. 1970. Environment and plant response.Mc Graw Hill Book Company 422 pp.

Zhou, B., Hu, C., Wang, H., Guo, R., Meng, M.Q.H., 2007. A wireless sensor network for pervasive medical supervision. IEEE ICIT 2007 - 2007 IEEE Int. Conf. Integr. Technol. 740744.

doi:10.1109/ICITECHNOLOGY.200 7.4290419 

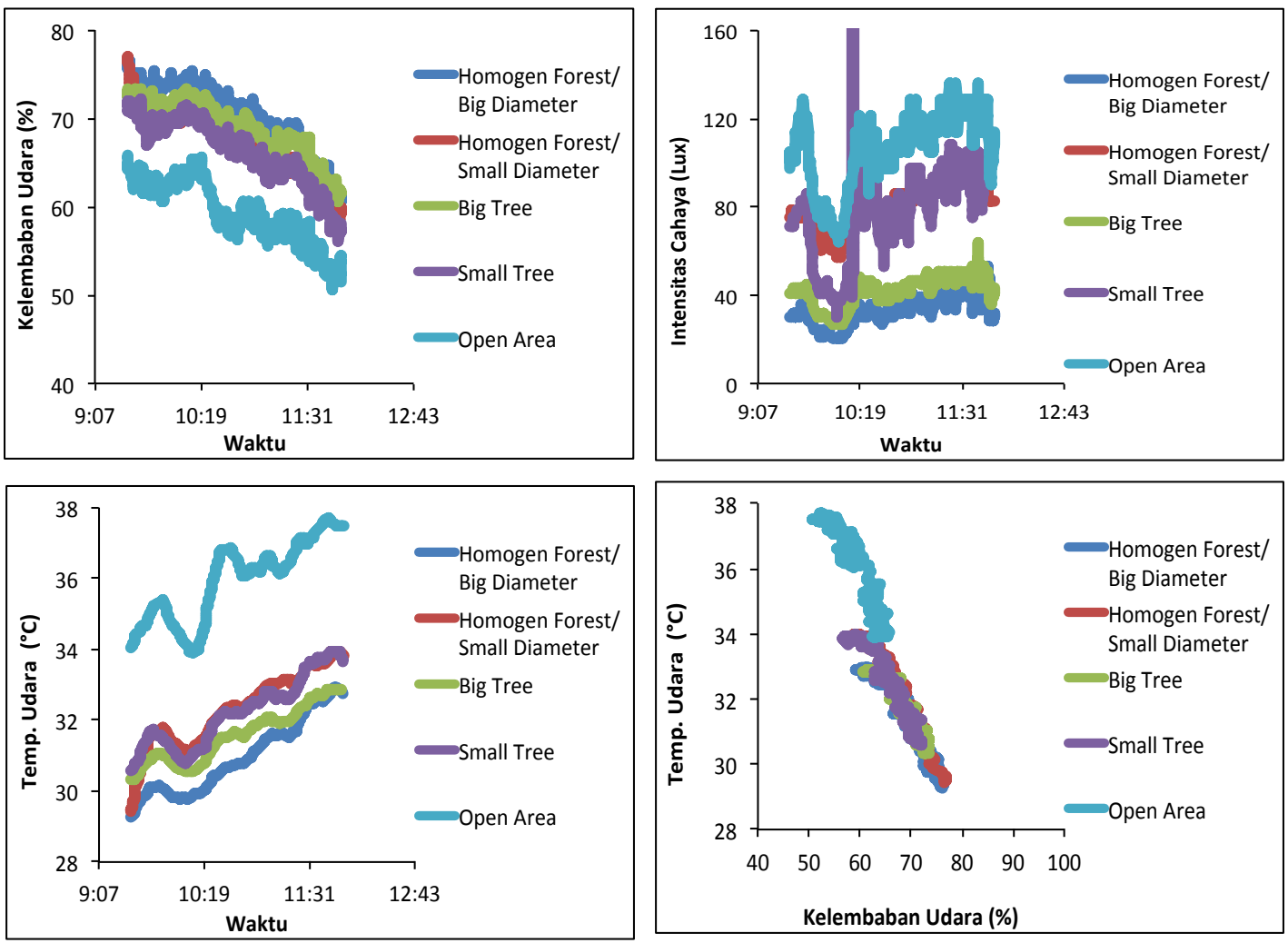

Gambar 1. Hasil pengukuran kelembaban udara, temperatur udara, intensitas cahaya dan hubungan temperatur udara dan kelembaban udara di lokasi penelitian.
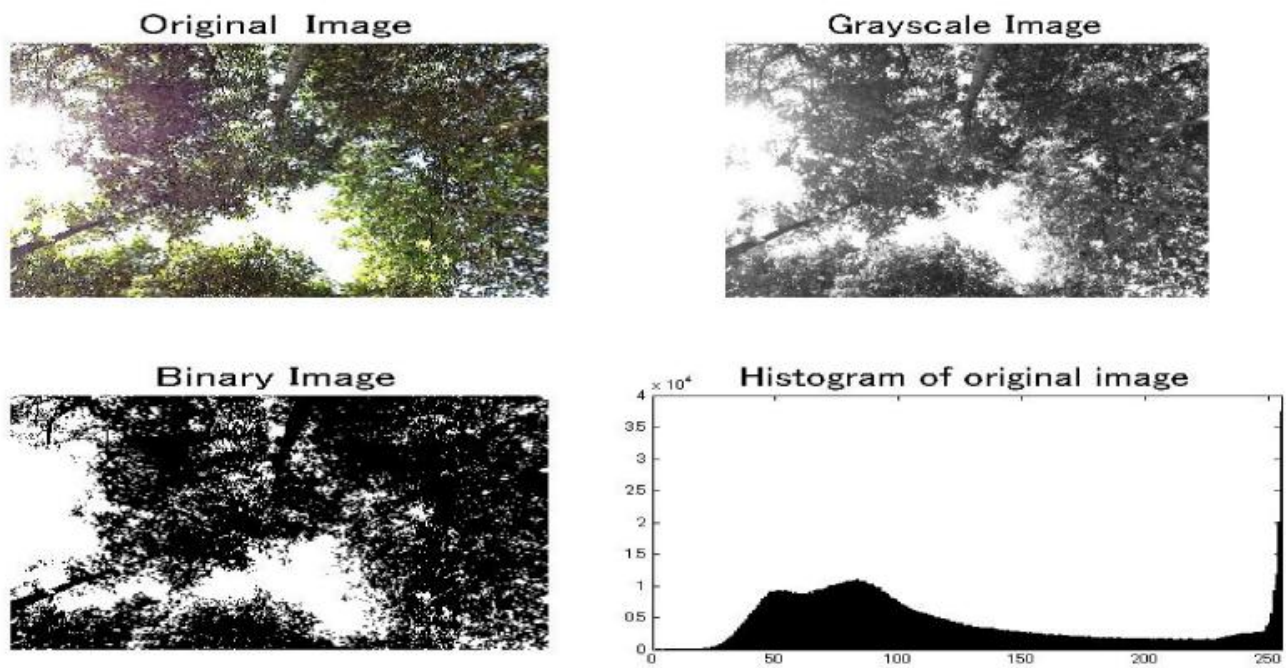

Gambar 2. Hasil pengolahan photo kanopi (Canopy Image) pohon/tanaman dengan menggunakan program Algoritma Canopy Binary dari Software Matlab@ 1994 - 2015.The MathWorks, Inc pada lokasi homogen forest/smalldiameter. 


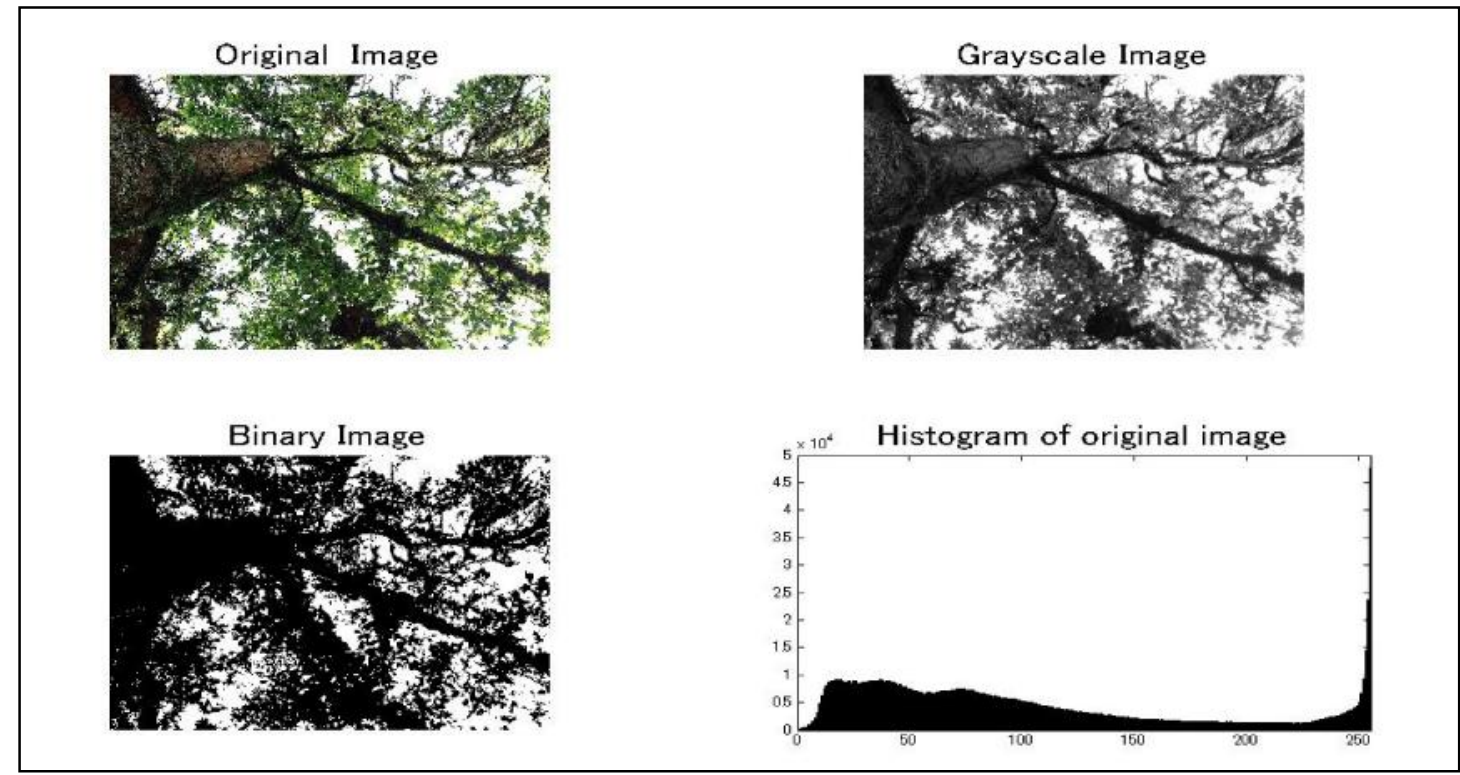

Gambar 3. Hasil pengolahan photo kanopi (Canopy Image) pohon/tanaman dengan menggunakan Program Algoritma Canopy Binary dari Software Matlab@ 1994 - 2015.The MathWorks, Inc pada lokasi homogen forest/big diameter. 